\title{
Clinical characteristics and outcomes of patients with strokeadmitted to three tertiary hospitals in Zimbabwe: A retrospective one-year study
}

\author{
Farayi Kaseke $^{1}$, Aimee Stewart ${ }^{2}$, Lovemore Gwanzura ${ }^{1}$ James Hakim $^{1}$, Vasco Chikwasha ${ }^{1}$ \\ 1. Department of Rehabilitation, College of Health Sciences, University of Zimbabwe, Harare, Zimbabwe \\ 2. Department of Physiotherapy, School of Therapeutic Sciences, University of the Witwatersrand, Johannesburg, South Africa \\ Correspondence: Mrs Farayi Kaseke (farayi.kaseke@gmail.com)
}

\section{Background}

\section{Abstract}

Epidemiological data on stroke in Zimbabwe are scarce and few clinical studies have been performed to date.

Methods

A retrospective review of the medical records of patients admitted for stroke during the year 2012 was performed at three tertiary hospitals. Sociodemographic data were recorded alongside with comorbidities and outcomes. Scoping over a period of one year using records of patients admitted for stroke helped to quantify and qualify the stroke problem. Descriptive analysis was done using STATA version 13.0.

Results

A total of 450 stroke cases, (63\% women) were included in the final analysis. The proportion of stroke cases among the admissions was $0.61 \%$. Mean age of the stroke patients was $61.6 \pm 16.8$ years $(95 \% \mathrm{CI}=60.1 ; 63.2)$. Risk factors were hypertension $(58.5 \%)$, diabetes $(18 \%)$ and HIV, (14\%)). Diagnosis was clinical and $39.4 \%$ had a CT scan. Mean length of hospital stay was $8.1 \pm 5.6$ days with a significance difference noted among hospitals $(\mathrm{p}<0.001)$. In-hospital mortality was $24.9 \%, 95 \% \mathrm{CI}(20.9 ; 29.0 \%)$. Mortality was associated with place of admission $(\mathrm{p}<0.001)$. Gender and side of stroke were significantly associated $(\mathrm{p}<0.001)$.

Conclusions

The sociodemographic characteristics mirrored findings from elsewhere. Mean age was higher than reported for Zimbabwe in the nineties and lately for Malawi. Majority of patients were female, elderly and hypertensive in line with findings from other countries. Presence of HIV is supported by recent studies from Malawi and South Africa. The relationship between gender and side affected needs further research. There is need to standardise acute care through proper diagnosis to reduce mortality. There is need to support caregivers post-discharge.

Data-handling is poor and there is limited capacity for Sub Saharan Africa hospitals to provide optimal stroke care. This may have long term implications on the outcome of survivors and caregivers. There is need of vigilance in acute stroke care.

\section{Introduction}

As first highlighted in the early nineties, stroke continues to be a public health issue in Zimbabwe. ${ }^{1}$ Although the prevalence of stroke in Sub Saharan Africa (SSA) was said to be less than half that of developed countries, ${ }^{2}$ the burden of stroke seems to be on the increase with a major impact on society. ${ }^{3,4}$ Recent studies show that incidence of stroke is comparable in developing and developed parts of the world. ${ }^{5}$ Data on the extent of this increase in the region is however, limited with much of it coming from South Africa and recently from Malawi. ${ }^{6}$ This increase of stroke in Sub-Saharan Africa is attributed to a surge in noncommunicable diseases, HIV, and an emerging vascular disease epidemic attributed to urbanisation. ${ }^{4,910,11}$ A difference in hypertension levels was found between rural and urban dwelling stroke patients, with lower numbers in the rural dwellers. ${ }^{12,13}$ A $40 \%$ higher rate of ischaemic stroke was found in HIV patients compared to HIV-negative controls. ${ }^{8}$ Although the HIV incidence in Zimbabwe has decreased over the last 20 years from 3\% to $1.2 \%{ }^{15}$ then to $0.74 \%$ in $2015^{15}$ there are still many people living with HIV who may be predisposed to stroke. There is however no literature with regard to the prevalence of HIV among patients with stroke in Zimbabwe.

Most people who suffer a stroke (patients) may not present to hospitals hence hospital based data is not the best to give an accurate picture of the epidemiology of stroke in SSA $^{4,13}$ and Zimbabwe in particular. Some patients may die soon after stroke while others may not go to hospitals as their symptoms maybe mild or if they cannot afford the hospital costs for services ${ }^{13}$ or better still seek help elsewhere affecting hospital data. Community based studies to get adequate information on stroke have been recommended. ${ }^{4}$ These are however expensive and not affordable for most researchers. Epidemiological data on stroke in Zimbabwe is scarce and reports available are quite old..$^{1,13}$ The authors ${ }^{1,13}$ reported a rise in the incidence of stroke in Zimbabwe from $31 / 100,000$ to $57 / 100,000$ in a decade. In the first study most of the patients were in the economically active group with mean age of 52, and less than a third were 65 years or older which when compared to the World Health Organization multicentre stroke registry, ${ }^{16} 54 \%$ of all patients were older than 64years. This difference reflected the difference in age structure between Zimbabwe and developed countries.

With regards to mortality in stroke, similar fatality rates ranging from $22 \%$ to $58 \%$ at one month following stroke were reported in Zimbabwe and other African studies. ${ }^{1,3,17}$ Cumulative mortality at three months was found to be $25.5 \%$ in South Africa. ${ }^{18}$ The same authors ${ }^{18}$ also reported a mean length of hospital stay of $6 \pm 4$ days. Thus, patients are discharged to the community while still needing further care. ${ }^{14}$ Elsewhere, findings show higher mean length of hospital 
Table 1: Proportion of patients admitted with stroke at the three hospitals in 2012

\begin{tabular}{lcccc}
\hline Study site & $\begin{array}{c}\text { Total admissions } \\
\mathbf{n}(\mathbf{\%})\end{array}$ & $\begin{array}{c}\text { Total stroke } \\
\mathbf{n}(\mathbf{\%})\end{array}$ & $\begin{array}{c}\text { Retrieved records } \\
\mathbf{n}(\%)\end{array}$ & $\begin{array}{c}\text { Proportion of stroke } \\
\text { admissions n (\%) }\end{array}$ \\
\hline Harare Hospital & $50,191(58.2)$ & $141(26.6)$ & $83(58.9)$ & 0.28 \\
Parirenyatwa Hospital & $34,617(40.1)$ & $276(52.1)$ & $276(100)$ & 0.80 \\
Chitungwiza Hospital & $1465(1.7)$ & $113(21.3)$ & $91(80.5)$ & 7.71 \\
\hline Total & 86,273 & 530 & $450(84.9)$ & 0.61 \\
\hline
\end{tabular}

Table 2: Sociodemographic characteristics, alcohol use, and smoking among patients with stroke

\begin{tabular}{lllcl}
\hline $\begin{array}{l}\text { Demographic } \\
\text { characteristics }\end{array}$ & Male n (\%) & Female n (\%) & $\begin{array}{c}\text { Total } \\
(\mathbf{N}=\mathbf{4 5 0})\end{array}$ & Missing data \\
\hline Gender & $164(37)$ & $282(63)$ & $\mathbf{4 4 6}$ & 4 \\
\hline $\begin{array}{l}\text { Age (mean years } \pm \\
\text { standard deviation) }\end{array}$ & $62.3 \pm 16.6$ & $61.0 \pm 16.9$ & $61.6 \pm 16.79$ & \\
\hline
\end{tabular}

\section{Marital status}

$\begin{array}{rllc}\text { Married } & 105(75.4) & 133(64.9) & 238(58.5) \\ \text { Single/Widowed } & 40(24.6) & 72(35.1) & 169(41.5) \\ \text { Total } & \mathbf{1 4 5} & \mathbf{2 0 5} & \mathbf{4 0 7}\end{array}$

Mode of payment

for hospital

services

\begin{tabular}{|c|c|c|c|}
\hline Cash & $79(50.3)$ & $135(48.9)$ & $214(49.4)$ \\
\hline Medical insurance & $10(6.4)$ & $20(7.2)$ & $30(6.9)$ \\
\hline $\begin{array}{r}\text { Social dimension } \\
\text { fund }\end{array}$ & $3(1.9)$ & $2(0.7)$ & $5(1.2)$ \\
\hline Pensioners & $65(41.4)$ & $119(43.1)$ & $184(42.5)$ \\
\hline
\end{tabular}

$\begin{array}{lllll}\text { Total } & 157 & \mathbf{2 7 6} & \mathbf{4 3 3} & 17\end{array}$

Alcohol use

$\begin{array}{cccc}\text { Yes } & 75(48.1) & 17(6.4) & 92(21.8) \\ \text { No } 81(51.9) & 249(93.6) & 330(78.2)\end{array}$

$\begin{array}{lllll}\text { Total } & 156 & 266 & 422 & 28\end{array}$

\section{Smoking}

\begin{tabular}{|c|c|c|c|}
\hline Yes & 53 (34.9) & $11(4.2)$ & $64(15.3)$ \\
\hline No & $99(65.1)$ & $254(95.8)$ & $353(84.7)$ \\
\hline Total & 152 & 265 & 417 \\
\hline
\end{tabular}


Table 3: Side of stroke by patient gender

\begin{tabular}{lcccc}
\hline & Left & Right & Bilateral & $\begin{array}{c}\text { Total } \\
(\mathbf{N}=\mathbf{4 5 0})\end{array}$ \\
\hline Male & $56(12.9 \%)$ & $81(18.7 \%)$ & $23(14.0 \%)$ & \\
Female & $119(27.4 \%)$ & $138(31.8 \%)$ & $17(6.2 \%)$ & \\
\hline Total & 175 & 219 & 40 & 434 \\
\hline Missing data & & & & 16 \\
\hline
\end{tabular}

Table 4: Comorbid conditions

\begin{tabular}{lcccc}
\hline Condition & Yes (\%) & No (\%) & $\begin{array}{c}\text { Total } \\
(\mathbf{N}=\mathbf{4 5 0})\end{array}$ & $\begin{array}{c}\text { Missing } \\
\text { data }\end{array}$ \\
\hline HIV & $63(14.0)$ & $5(7.4)$ & 68 & 382 \\
Hypertension & $263(58.4)$ & $187(41.6)$ & 450 & 0 \\
Diabetes Mellitus & $81(18.0)$ & $8(8.9)$ & 89 & 361 \\
$\begin{array}{l}\text { Heart Disease } \\
\begin{array}{l}\text { Aspiration } \\
\text { Pneumonia }\end{array}\end{array}$ & $25(5.6)$ & $8(22.2)$ & 33 & 417 \\
\hline
\end{tabular}

stay due to ability to pay for services. ${ }^{2,19}$ This study aimed to describe the clinical characteristics and the outcomes of patients with stroke admitted at three tertiary hospitals in Zimbabwe between January and December 2012.

\section{Methods}

\section{Study design}

This was a retrospective cross-sectional study based on hospital records.

\section{Participants and research setting}

Records of patients admitted for stroke during the year 2012 were retrieved. The study was carried out at Chitungwiza, Harare and Parirenyatwa central hospitals in Zimbabwe. These are major public referral hospitals. The staff working at these hospitals are trained to be able to diagnose stroke. Only one hospital (Parirenyatwa) has a CT scan and the other hospitals refer to other centres for this service. None has a Magnetic Resonance Imaging (MRI) for confirming in case there is any doubt with the clinical diagnosis. The authors only relied on the diagnosis as entered in the patients' files in the records. Not all patients therefore had a stroke confirmation.

\section{Study procedures}

Patients admitted with a diagnosis of stroke ${ }^{20,21}$ between January and December 2012 were identified from the ward admission registers. The names and hospital identification numbers of the patients were used to retrieve their records. Four hundred and fifty records were reviewed and the following data were collected (age, gender, marital status, employment status, level of education, type of stroke, dates of admission, discharge or death and history and results of CT scan) and recorded on a data abstraction sheet. Stroke risk factors including diabetes mellitus, hypertension, heart disease (both structural and atrial fibrillation), current or past history of smoking or alcohol consumption and HIV status were examined. Presence of aspiration pneumonia as a complication of stroke was also noted. The method of payment for hospital services which included payment using cash, medical insurance, social dimension fund and patients above 65 years do not pay was recorded.

\section{Statistical analysis}

Data were analysed using Stata 13 to generate means and standard deviations, and proportions with their 95\% confidence intervals where appropriate.

\section{Ethical considerations}

Ethical approval for the study was provided by the University of Zimbabwe College of Health Sciences and Parirenyatwa Hospital Joint Ethics Committee (JREC 324/12) and The Medical Research Council of Zimbabwe (MRCZ/A/1738). Data collection forms were anonymised to ensure confidentiality.

\section{Results}

During the 12 month review period, a total of 86,273 patients were admitted at the three hospitals. Of these 530 $(0.61 \%)$ were diagnosed as having a stroke and $450(85 \%)$ records for stroke patients were successfully retrieved. Some of the records had incomplete information. Missing data were treated as missing. Higher proportion of stroke cases among the admissions $(7.7 \%)$ was at Chitungwiza hospital where the mortality rate was also highest (Table 1).

\section{Types of stroke and side affected}

Stroke diagnosis was based on the clinical assessments by physicians. Approximately $39.4 \%$ had a CT scan done. No post mortem reports on any of the deaths were done to suggest type of stroke. Taking into account that some data were missing, $175(40.3 \%)$ patients had a stroke on the left side of the brain, $219(50.5 \%)$ had a stroke on the right, 40 $(9.2 \%)$ had a stroke on both sides. Both gender and side of stroke was mentioned in 434 patients. Fifty-six $(12.9 \%)$ males had a left sided stroke while 119 (27.4\%) females had a left stroke. Eighty-one $(18.7 \%)$ males had a right stroke while $138(31.8 \%)$ females had a right stroke. More male patients $(14 \%)$ than females $(6.2 \%)$ had stroke on both sides. Chi Square test showed an association between gender and

Table 5: Mortality among patients with stroke

\begin{tabular}{lcccc}
\hline Hospital & $\begin{array}{c}\text { Alive } \\
\mathbf{n}(\mathbf{\%})\end{array}$ & $\begin{array}{c}\text { Dead } \\
\mathbf{n}(\mathbf{\%})\end{array}$ & $\begin{array}{c}\text { Total } \\
(\mathbf{N}=\mathbf{4 5 0})\end{array}$ & $\begin{array}{c}\text { 95\% confidence } \\
\text { interval }\end{array}$ \\
\hline $\begin{array}{l}\text { Chitungwiza } \\
\text { Hospital }\end{array}$ & $58(68.2 \%)$ & $31(34.8)$ & 89 & 24.7 to 44.9 \\
Harare Hospital & $68(91.9 \%)$ & $6(8.1 \%)$ & 74 & 1.7 to 14.5 \\
$\begin{array}{l}\text { Parirenyatwa } \\
\text { Hospital }\end{array}$ & $199(73.7 \%)$ & $71(26.3 \%)$ & 270 & 21.0 to 31.6 \\
\hline Total & $325(75.1 \%)$ & $108(24.9 \%)$ & 433 & \\
\hline
\end{tabular}


side of stroke with more females presenting with stroke on the left side of the brain $(\mathrm{p}=0.011)$. Haemorrhagic stroke was reported in 225/417 (54.0\%) while $192(46.0 \%)$ had ischaemic stroke but only 180 had history of CT scan taken, confirming diagnosis was therefore not done.

\section{Comorbid conditions}

Two hundred and sixty-three (58.4\%) patients were known hypertensives or were on treatment for hypertension. Sixty -eight patients were tested for HIV and among these 63/68 $(14.0 \%$ of 450$)$ were HIV positive. Mean age of the $63 \mathrm{HIV}$ positive patients was $46 \pm 15.1$ years compared to the group mean age of $61.7 \pm 16.8$ years. Eighty-nine patients were tested for Diabetes mellitus (DM) and 18.0\% had diabetes. Approximately $6.0 \%(n=25)$ had a history of some heart disease. Aspiration pneumonia was diagnosed in $9.0 \%$ (Table 4).

\section{Mortality rates}

There were $108(25 \%)$ in-hospital deaths. Slightly above $30.0 \%$ males (30.3\%: 95\% CI $=22.9 ; 37.6)$ and females $(22.0 \%$ : CI 95\% CI=17.1; 26.9) died in hospital. This was not statistically significant $(\mathrm{p}=0.059)$ although proportionally more males died. Eighteen (44.0\%) patients with aspiration pneumonia died in hospital. Fifteen (23.8\%) HIV positive patients died in-hospital. Using Fisher's exact test, there was no difference in mortality between HIV+ and HIV- patients $(p=1.000)$. Thirty-five per cent of the patients died in hospital at Chitungwiza. There was a statistically significant association between admitting hospital and mortality with more patients dying at Chitungwiza $(\mathrm{p}<0.001)$ (Table 5). When type of stroke was tabulated against mortality, fortynine (out of 187) $(26.2 \%$ : 95\% CI=19.8;32.6) of the patients with ischaemic stroke died while 51/214 (23.8\% 95\% CI= 18.1;29.6) died among haemorrhagic strokes. No difference in mortality was found between haemorrhagic and ischaemic strokes $(\mathrm{p}=0.584)$.

\section{Length of hospital stay}

The mean length of hospital stay was $8.1 \pm 5.7$ days (CI 7.5; 8.6). Patients stayed longer at Harare (11.5 \pm 4 days) (CI 10.6;12.4) and fewer days at Chitungwiza (5.7 \pm 3 days) (CI 5.1;6.4). The length of hospital stay at Parirenyatwa was $7.8 \pm 6.3$ days $)(\mathrm{CI}=7.0 ; 8.5)$. Analysis of variance showed a significant difference in length of stay between hospitals. Patients stayed longer at Harare than at the other hospitals $(\mathrm{p}<0.001)$.

\section{Discussion}

This study describes the clinical characteristics and outcomes of patients with stroke admitted at three tertiary hospitals in Zimbabwe during the year 2012. The available data did not make it possible to calculate the prevalence or incidence of stroke in Zimbabwe therefore no comparison can be made with other countries because the of the study setting. However, the results provide important information about stroke in Zimbabwe. Of importance is the fact that clinical diagnosis was used, ${ }^{20}$ as less than half of the patients had a CT scan done. This is different from other studies, ${ }^{6}$ where both CT Scan and MRI were used to confirm diagnosis. The study missed cases that die soon after stroke while at home and those people with mild strokes who do not present to hospitals. It is assumed that many people who suffer strokes do not make it to hospital and Community based studies have therefore been recommended by authors as the study method of choice. ${ }^{21-25}$ Stroke patients were mainly elderly females who had no source of monthly income. This matches studies done elsewhere where $52 \%$ to $68 \%$ of strokes were women. ${ }^{18,26-29}$ However studies in Malawi have reported a lower proportion of females. ${ }^{7}$ The mean age was lower than for European studies ${ }^{30}$ but higher than for Malawi. Traditionally stroke was a disease of old age, but findings of stroke among the under 20 s and the middle aged has led to the conclusion that stroke should no longer be regarded as a disease of old age. ${ }^{5}$ The worldwide epidemic of diabetes ${ }^{31}$ and increasing prevalence of cardiovascular risk factors in young adults has compounded this. ${ }^{32}$ The high prevalence of HIV in younger people and its relationship with stroke $\mathrm{e}^{6,11,38}$ makes stroke a disease of all ages. In this study it seems as if only those who had indications for HIV testing were tested, so an unknown number of HIV positive may have been in those that were not tested. The $14 \%$ prevalence of HIV is close to the adult population prevalence of 15\% (ZDHS 2010/11) ${ }^{15}$ and these had low mean age. The Provider initiated counselling and testing policy for HIV in Zimbabwe should be strengthened in stroke. In higher income countries, $15 \%$ of the population is over the age of 65 whereas these are less than $5 \%$ in most African countries. Age standardised rates would assist since the gender difference may be due to women surviving longer. Since this was a records review, no information about daily quantity of tobacco smoked or alcohol consumed was available to assess any association with stroke. Other confirmed risk factors for stroke like hypertension, diabetes and heart disease were found. $1,5,6,18,30,35,37$ Awareness at Community awareness with regards to stroke prevention from modifiable risk factors is important.

A limitation of our study was the low uptake of CT scans for the majority of patients as they lacked resources or lack of health insurance cover. ${ }^{22,30} \mathrm{CT}$ scans are important for accurate early diagnosis and classifying of strokes as this has implications on the management and prognosis of stroke. ${ }^{2}$ Most strokes were reported as haemorrhagic, mirroring reports by Sagui ${ }^{2}$ but contrasting Nigerian, ${ }^{33}$ Croatian, ${ }^{34}$ and other studies ${ }^{5,35,36}$ that reported higher incidences of up to $73 \% 18,29$ ischaemic strokes. More data may be available as haemorrhagic patients are very ill so extra effort to have CT scans is made. Haemorrhagic strokes are associated with hypertension and this was found to be high among these patients and in other studies. The management of ischaemic and haemorrhagic stroke differs substantially, and therefore their differentiation and identification of stroke complications is important in acute stroke. A reliable differentiation is not possible on the basis of clinical examination alone ${ }^{38}$ hence need for CT scan. An increase in proportion of hypertension from $1997^{1}$ points towards an increase in vascular disease in Zimbabwe. Studies elsewhere have also reported a higher prevalence of hypertension among patients with ischaemic stroke. ${ }^{3} 4$ It is not clear why more females were affected on the left side. There may be genetic or structural differences between the sexes that may warrant further research. The length of hospital stay was higher than for studies done elsewhere. ${ }^{18,30}$ In other places patients are discharged as soon as they are stable, to create space for others or due to lack of finances. Longer hospital stay may mean that patients get better management rather than go home early to an unprepared family. However, this may mean higher hospital costs which patients cannot afford. It is important for the centres to balance the length of stay with health benefits for the patients. In developed 
countries it is higher as medical bills are covered by health and social insurance unlike in most developing countries. ${ }^{19,39}$ Community Based Rehabilitation through the involvement of family caregivers may be a management of choice as a way for continuity of care. This will require educating the caregivers in the care of stroke survivors. Mortality was higher than elsewhere where cumulative mortality to the first three months post stroke ranged from 3-30\%. ${ }^{7,18,30,33}$ A $41 \%$ mortality rate was reported in Gambia which was higher. ${ }^{17}$ The lowest rates were found in USA, probably due to their well-resourced health care system. There is a need to understand underlying dynamics of stroke management in Zimbabwe. The researchers postulated weaknesses in the acute care management of stroke patients at the three institutions. Less adequate stroke management has been associated with greater case fatality. ${ }^{5}$ We also assumed that patients may take longer to present to hospitals and only do so when complications have set in hence the higher mortality. The point at which patients present to hospital may affect outcomes even though scans may be done early. Statistics for those that die at home are never captured hence community based studies are recommended. ${ }^{21,22}$ It is also not clear how much HIV is contributing as many had an unknown status. Outcome may be improved by a case review approach as this would include reflection on the duration of symptoms at the point of admission in each of the three facilities. The health delivery system in Zimbabwe should make stroke management a priority to reduce mortality reported to be $107 / 100,000^{15}$ through proper diagnosis and treatment. There is a need for more studies on the contribution of aspiration pneumonia to mortality. Studies elsewhere have pointed towards a relationship between stroke and aspiration pneumonia. ${ }^{40,41}$ Elsewhere ${ }^{42}$ stroke units have been found to reduce length of stay and fatality in stroke patients and this is recommended for this setting.

This was a retrospective records review study and as such there was a lot of missing information from the records and this is likely to cause bias. The medical records are paper based and manually filed leading to incompleteness and a lack of consistency. This made it difficult to obtain important epidemiological data which is necessary to plan for and provide better services for patients. There is therefore a need to identify better ways of recording patients' data at these centres. Poor data keeping may affect both practice and research in that lack of information on the type of stroke may affect timely and appropriate intervention and lack of information affects data needed in research. ${ }^{20}$ This is however a common problem with records review studies. ${ }^{1}$ As it was a hospital based study, generalizability of the findings is limited. The authors did not use methods that have been used elsewhere such as clinical audit checklist, root cause analysis which could have assisted in assessing contributory factors for each stroke. Records review studies may under estimate the prevalence of stroke in these areas as most patients may not come to hospital.

\section{Conclusions}

Although records had some missing information, the results give some insight into the stroke problem in Zimbabwe. We designed this retrospective study to describe the clinical characteristics and outcome of patients admitted for stroke in three tertiary hospitals in Zimbabwe. Data management is poor and there is limited capacity in Sub Saharan Africa hospitals to provide optimal stroke care. Prospective studies will give a better picture of the burden of stroke in our setting. The researchers recommended the need to do a full and proper assessment especially for conditions that are associated with stroke to help plan for prevention and rehabilitation strategies such as physiotherapy. Routine testing of HIV in people affected by stroke should be done. There is also need for better funding for stroke care so that patients may stay in hospital until they are more functional.

\section{Acknowledgements}

Authors wish to acknowledge the participating hospitals.

This work was supported by Grant number 2U2RTW007367 from the Fogarty International Centre, National Institutes of Health (NIH, USA) through the International Clinical, Operational and Health Services and Training Award (ICOHRTA)".

\section{Competing interests}

The authors declare no financial or personal relationships that may have inappropriate effects on the outcomes of this research

\section{References}

1. Matenga J (1997). Stroke incidence rates among black residents of Harare. A prospective community based study. South African Medical journal. 87; 606-608.

2. Sagui E, M'Baye PS, Dubecq C; Fall KB, Niang A, Gning S, Bellefleur JP, Sane M, Debonne JM. Ischemic and Hemorrhagic Strokes in Dakar, Senegal. A Hospital-Based Study. Stroke. 2005;36:1844-1847.

3. Connor MD, Rheeder P, Bryer A, et al. The South African Stroke risk in general practice study. S Afr Med J 2005; 95 (5):334-9

4. Walker R, Whiting D, Unwin N, et al. Stroke incidence in rural and urban Tanzania: a prospective, community-based study. Lancet Neurol 2010; 9: 786-92

5. Feigin VL, Forouzanfar MH, Krishnamurthi R, et al. Global and reginal burden of stroke during 1990-2010: findings from the Global Burden of Disease Study 2010. Lancet 2014; 383:245-254

6. Benjamin LA, Corbett EL,Connor MD, et al. HIV, antiretrociral treatment, hypertension, and stroke in Malawian adults: a case-control study. Neurology 2016. 86: 324-332.

7. Heikinheimo T, Chimbayo D, Kumwenda JJ, Kampondeni S, Allain TJ. Stroke outcomes in Malawi, a country with high prevalence of HIV: a prospective follow-up study. PLoS One 2012;7:e33765

8. Mascolini M. Ischaemic Stroke rate $40 \%$ higher in HIV, but not if CD4s top 500. International AIDS Society. 2014; Retrieved from http:// www.iasociety.org/Default.aspx? Page1d=5\&elementid=15995.

\section{Mochan A, Modi M, Modo G . Stroke in Black South African}

HIV- Positive patients. Stroke. 2003; 34:10-15. Retrieved from [http:/ stroke.ahajournals.org/content/34/1/10.full on 03 May 2014].

10. Thorogood M, Connor M, Tollman S. et al. A cross sectional study of vascular risk factors in a rural South African population: data from the Southern African Stroke Prevention Initiative (SASPI).BMC Public Health 2007; 7:326 [http://dx.doi.org/10.1186/1471-2458-7-326].

11. Ssinabulya I, Kayima J, Longenecker C, et al. Subclinical Atherosclerosis among HIV-Infected Adults Attending HIV/AIDS Care at Two Large Ambulatory HIV Clinics in Uganda. PLoS One 2014;9(2):e89537.

12. Walker RW, Jusabani A, Aris E, et al. Stroke risk factors in an incident population in urban and rural Tanzania: A prospective, community-based, case control study. The Lancet Global Health, 2013; 1(5):282-288. 
13. Matenga J, Kitai I, Levy L. Research from the South, Strokes among black people in Harare Zimbabwe: results of computed tomography and associated risk factors. BMJ. 1986; 292, June 21, 1649-1652.

14. WHO (2011). Health profile: World health rankings. Stroke in Zimbabwe. Retrieved from http://www.worldlifeexpectancy.com/ country-health-profile/Zimbabwe on 14/12/2011.15. Zimbabwe Demographic Health Survey (ZDHS) 2010/11

16. S. Hatano. Experience from a Multicentre stroke register: a pleriminary report. Bulletin in the World Health Organisation. 197654(5):541-53.

17. Walker RW, Rolfe M, Kelly PJ, et al. Mortality and recovery after stroke in the Gambia. Stroke. 2003; 34:1604-1609.

18. Mudzi W, Stewart A, Musenge E. Case fatality of patients with stroke over a 12-month period post stroke. S Afr Med J. 2012; 102(9).

19. Al Oraibi S. Demographic characteristics of stroke patients in developing countries. Example from Jordanian government hospitals Journal of Public Health and Epidemiology 2012; 4(5). 110-116. http:// www.academicjournals.org/JPHE

20. Aho K, Harmsen P, Hatano S, et al. Cerebrovascular disease in the community: results of a WHO Collaborative Study. Bulletin of the World Health Organisation, 1980.58 (1): 113-130.

21. Garbusinski JM, van Sande MAB, Bartholome EJ, et al. Stroke Presentation and outcome in developing countries: A prospective study in the Gambia. Stroke. 2005; 36:1388-1393.

22. Connor MD, Walker R, Modi G, et al. Burden of stroke in black populations in sub Saharan Africa. Lancet Neurol 2007; 6: 296-278 [http://dx.doi.org/10.1016/S1474-4422(07)70002-9]

23. Rosman KD. The Epidemiology of stroke in an urban black population. Stroke. 1986; 17:667-669.

24. Joubert J. The Medunsa stroke data bank. An analysis of 304 patients seen between 1986 and 1987. S Afr Med J 1991; 80:567-570.

25. Dalal S, Beunza J J, Volmink J, et al. Non-communicable diseases in Sub-Saharan Africa: what we know now; International Journal of Epidemiology 2011; 40(4):885-901.

26. Foerch C. Exploring gender distribution in patients with acute stroke: A multinational approach. Journal of Research in Med. Science. 2013, Jan: 18(1):10-6.

27. Harirchian MH, Ghaffarpour M, Doratotaj D, et al. Stroke in young Adults. A prospective study of 68 cases. ActaMedicalIronica, 2006;11(17):119-124,

28. The University Hospital. Stroke statistics. TheUniversityHospital. com. University of Medicine and Dentistry OF New Jersey. Newark. New Jersey.

29. De Villiers L, Badri M, Ferreira M, et al. Stroke outcomes in a socio-economically disadvantaged urban community. S Afr Med J 2011; 101(5): 345-348.
30. Hall MJ, Levant S, DeFrances CJ. Hospitalisation for stroke in US hospitals (1989-2009). National Centre for Health Statistics. Data Brief number 95. 2012.

31. Danael G, Finucane $\mathrm{MM}<\mathrm{LuY}$ et al. National, regional, and global trends in fasting plasma glucose and diabetes prevalence since 1980: systematic analysis of health examination surveys and epidemiologicals studies with 786 country years and 5.4 million participants. Lancet 2011;377:568-86

32. Kissela BM, Khoury JC, Alwell K et al. Age at stroke: temporal trends in stroke incidence in a large, biracial population. Neurology 2012; 79:1781-87

33. Oni A, Eweka A, Otunga P, et al. The Incidence and pattern of stroke in Bayelsa State Nigeria, The Internet Journal of Third World Medicine. 2009; Volume 8.

34. Bilic I, Dzamonja G, Lusic I et al. Risk factors and outcome differences between ischaemic and haemorrhagic stroke. Acta Clin Croat 2009; 48:399-403.

35. Benjamin, L.A. Bryer, A., Khoo, S et al. HIV infection and stroke: current perspectives and future directions. Lancet Neurology, 2012; 11(10), pp.878-890

36. Cole JW, Pinto PN, Hebel JR, et al. Acquired Immunodeficiency syndrome and the risk of stroke. Stroke 2004; 35:51-56.

37. Connor MD, Thorogood M, Casserly B, et al. Prevalence of stroke survivors in Rural South Africa: results from the Southern African Stroke Prevention Initiative (SASPI)

Agincourt Field Site. Stroke 2004; 35(3):627-632. [http://dx.doi. org/10.1161/01.STR.0000117096.61838.C7].

38. Maurer M, Shambal M, Berg D, et al. Differentiation between Intracranial haemorrhage and ischaemic stroke bt transcranial colourcoded duplex sonography. Stroke 1998;29:2563-2567.

39. van Straten A, van der Meulen JHP, van den Bos GAM, et al. Length of hospital stay and discharge delays in stroke patients. Stroke 1997; 28:137-140.

40. Teasell RW, McRae M, Marchuk Y et al. Pneumonia associated with aspiration following stroke. Arch Phys Med Rehabil. 1996; 77(7): 7079 .

41. Katzan IL, Cebul RD, Husak SH et al. The effect of pneumonia on mortality among patients hospitalised for acute stroke. Neurology 2003; 60(4):620-625

42. Donnan GA, Fisher M, Macleod M, Davis SM. Stroke. Lancet,2008; 371(9624):1612-1623. 